\title{
Human centred science and technology — transdisciplinary foresight and co-creation as tools for active needs-based innovation governance
}

\author{
Niklas Gudowsky $^{1} \cdot$ Walter Peissl ${ }^{1}$ \\ Received: 14 July 2016 / Accepted: 13 October 2016/Published online: 22 October 2016 \\ (C) The Author(s) 2016. This article is published with open access at Springerlink.com
}

\begin{abstract}
Current governance structures are increasingly showing inability to address complex issues such as the Grand Challenges. Dealing with these highly interrelated, cross cutting, extensive and potentially open ended issues requires research, development and innovation to be oriented towards societal needs and demands. Here, developing and applying sustainable long term strategies for socio-technical change on the basis of socially robust knowledge seems inevitable and using the tools of anticipatory governance - forward looking and participation - is essential in order to govern innovation actively and responsibly. Yet, expert-based forward looking has its limits, especially when considering long term perspectives, and may fail to include all necessary opinions. Thus, stakeholder engagement has become a norm over the last decades, but including laypeople into forward looking science, technology and innovation (STI) governance is underexplored. Here, strategy and policy programme development may be well suited to function as early entry point for public needs and values into the innovation process. This paper will briefly review the theoretical basis for transdisciplinary forward looking and provide first insights into an ongoing highly deliberative and reflexive foresight and co-creation process engaging science, society and policy makers, CIMULACTCitizen and Multi-Actor Consultation on Horizon2020. We will especially focus on the role of technology within a collective visioning exercise that allowed for shared explorations of desirable futures, thereby collecting tacit knowledge as well as social needs and values. Integrating these with stakeholders' and experts' knowledge serves for co-creating socially robust
\end{abstract}

Niklas Gudowsky

niklas.gudowsky@oeaw.ac.at

1 Institute of Technology Assessment, Austrian Academy of Sciences, Strohgasse 45/5, 1030 Vienna, Austria knowledge for orienting policy and strategy programming towards needs based science, technology and innovation.

Keywords Transdisciplinarity · Participatory foresight . Co-creation · Visioning · Programme development $\cdot$ Research and innovation governance

\section{Towards needs based STI}

Current governance structures are increasingly showing inability to address complex issues such as the Grand Challenges with the needed speed or resolve [1]. The Grand Societal Challenges build the basis of the actual Framework programme of the EU (Horizon 2020). They address issues such as climate change, the ageing society or food security, which are highly interrelated, cross cutting, extensive and potentially open-ended issues. Dealing with them requires research, development and innovation to be oriented towards needs, demands and expectations of society. Unwanted side effects of socio-technical change can thus be minimized in advance and do not need to be regulated costly afterwards. Here, developing and applying sustainable long term strategies for socio-technical change seems inevitable for nourishing prosperous societies.

Using the tools of anticipatory governance-forward looking and participation - is essential in order to govern innovation actively and responsibly. Key principles of responsible research and innovation (RRI) recently given high prominence on EU and national level are therefore 'anticipation, reflection and deliberation in and around research and innovation, influencing the direction of these and associated policy' [2]. This entails mutual responsiveness between society and innovators, leading to higher acceptability, sustainability and desirability of innovation processes and products [3]. As a 
concept, RRI builds on 'technology assessment and foresight, application of the precautionary principle, normative/ethical principles to design technology, innovation governance and stakeholder involvement and public engagement' [4]. Gaining an understanding of futures is essential to RRI, and forward looking activities are therefore an integral part of the concept [5]. Therefore Foresight has been integrated in RRI toolkits $[6,7]$.

To increase flexibility, a more systematic embedding of Future-oriented Technology Analysis (FTA) - combining approaches of Foresight, Technology Assessment (TA) and forecasting - into science, technology and innovation governance is repeatedly called for [1, 8-11]. In Europe, Foresight and TA have increasingly contributed to political priority setting and strategic decision making over the last 30 years $[12,13]$, and recently a shift from narrow technology focussed approaches to broader perspectives of the entire socio-technical systems is recognized [14]. Innovation understood as complex process, often entails profound uncertainties and high risks, demanding large investments with late return, or stranded investments $[15,16]$. Within this setting, expectations are a main driver in shaping new technologies, often producing various forms of hype cycles along the way to market readiness or failure [17-19]. Here, Futures Studies support harnessing and orienting these expectations.

In shaping socio-technical change through informing STI policy, forward-looking activities can fulfil several functions: eliciting shared goals and visions among a group of participating actors from different sectors, creating and fostering new networks and structures, combining relevant information on current trends and future developments, as well as addressing system deficiencies and failures [12,13]. For instance, the collaborative development of cross-cutting challenges for European policy making that demand coordinated policy actions was supported by forward-looking activities [20,21]. Especially when dealing with the Grand Challenges, Futures Studies need to attend to the distinctive role of challenging predictions that are mainly based on extrapolated past events by emphasizing on creativity to present true alternatives [9]. Nevertheless, producing such socio-technical imaginaries may only shape futures appropriated to those engaged in the visioning process [22], whereas other - at times socially more robust - futures may become ever more inaccessible. This implies broad engagement strategies, moving away from reductionist experts-only-settings when creating such imaginaries.

This paper will briefly review the theoretical basis for transdisciplinary forward looking and provide insights into the tools of a highly deliberative and reflexive Foresight and cocreation process engaging science, society and policy makers: CIMULACT-Citizen and Multi-Actor Consultation on Horizon2020 [23]. Intermediate results include excerpts from Europe-wide citizens' visions and extracted social needs. Here, we will especially focus on the role of technology within this content. On this basis, we will elicit implications for governing sustainable human centred technologies. For the theoretical underpinnings of this paper, we mainly draw on literature from the established interdisciplines of Futures Studies, Technology Assessment, and sustainability science as well as science and technology studies (STS).

\section{Limits of expert-based forward looking}

When scientists act as experts, Nowotny [24] argues, they need to answer to questions they did not chose and therefore transgress the limits of their competence, by addressing issues that cannot be reduced to the purely scientific or technical, and by addressing a mixed audience, not only composed of fellow-experts. This is especially disadvantageous, when decision makers elicit expertise in times of high uncertainty when neither sufficient knowledge nor all necessary information is available, and thus expertise becomes vulnerable to contestation [24]. Additionally, many policy makers maintain relationships with so called 'pet' experts - experts that are consistently commissioned to provide a convenient and predictable opinion on certain topics, which can then be utilized in political arguments [25]. As a result, decision makers' and public confidence in expertise may diminish, if an issue is repeatedly contested by opposing experts' opinions that may be elicited almost at any time, due to prevailing uncertainty $[26,27]$.

This line of argumentation may especially hold true for policy and strategy advice produced by Futures Studies, a field where high uncertainty and thus many-possibly opposed or conflictive - options are often inherent to a single study, not mention several ones. On this matter, Grunwald [28] states that results of Futures Studies are prone to contestation as they are often controversial, divergent or even contradictory. Unsurprisingly, increasing time horizons significantly decrease the accuracy of technological forecasts [29]; and beyond short term prediction, expert anticipation of possible or probable futures become highly arbitrary [30, 31]. Future-oriented technology analysis also repeatedly fails to anticipate technological innovations with important social and economic effects [32]. Considering the disruptive potential of emerging technologies, Nordmann [33] even provokes by claiming that anticipating future effects of STI is impossible because anticipation only allows for anticipating changes 'in a world as we know it', not a changed one.

Against this backdrop, there is a distinct need for future studies to produce policy advice on the basis of socially robust knowledge. Such robustness is achieved through (a) testing for validity in the real world, (b) social distribution of expertise and the links built with other types of knowledge and experience, and (c) constant testing, expanding and modification [24, 34]. Endorsing public values in the innovation process is in need of interdisciplinary research to avoid contested 
technologies $[35,36]$. Transdisciplinary knowledge co-production, however, is recognized as effective in addressing and current sustainability challenges [37]. Here, transdisciplinary Foresight and co-creation may offer an additional value added.

\section{From participatory to transdisciplinary foresight}

Even though, forward looking activities have been and still are largely an experts' game, including a greater variety of actors and perspectives is a demand that practitioners and scholars have been articulating for decades [38, 39]. Participatory methods for Futures Studies have been discussed since the 1960's and over the last two decades practitioners developed and applied numerous participatory methods [40]. Here, stakeholder engagement has become a norm, but moving from interdisciplinary settings and stakeholders towards also including laypeople into forward looking activities can be increasingly observed [41-46]. Collective utopian thinking is seen as a tool for strategic long term thinking and transdisciplinary problem solving $[47,48]$. Being especially equipped for dealing with complex wicked problems - highly interrelated, cross cutting extensive and potentially open ended issues - such as the Grand Challenges, post normal solution oriented knowledge co-creation requires constructive inputs of various types of knowledge, including norms and values [49, 50]. Some authors see this as means for shifting leadership from an individual activity to a co-creative act [51]. Several reasons for public participation are established in literature; producing better decisions and raising legitimacy among the most relevant ones [52-55]. On EU-level, shaping citizenry and strengthening trust in EU institutions may be added [56, 57]. In correspondence to the established functions of participation practices, Wiek and Iwaniec [58] describe several process-level functions of collective visioning activities: building capacity, empowering stakeholders, creating ownership, and developing accountability. Despite increasingly becoming established, transdisciplinarity is far from being a standard tool for supporting decision making and several barriers remain in place, such as failing or absent mechanisms for translating outcomes of deliberative processes into policy making, decision makers' failing interest in or diffuse understanding of the use of such results, as well as slow and partial implementation of the participatory norm as laid out in EU constitutional treaties, that entails large room for interpretation [59-61].

The existing Futures Studies literature is somewhat sparse in assessing laypeople engagement. Popp [39] even calls for distinctive quality criteria for participatory Futures Studies as well as 'the essential involvement of participation-oriented researchers in the critical discourse of the scientific community'. In sustainability science for instance, a large body of literature on transdisciplinary, community-based, interactive, and participatory research approaches is available $[62,63]$. Within other disciplines, for instance STS and TA, public engagement (PE) with science and technology is a well investigated topic.

\section{Limits to public engagement}

Public engagement's faces are manifold, and it differs according to many variables including but not limited to the context it is applied in, scope, topic, sector, who is engaged when, what is their role and what is the aimed for outcome. Thus $\mathrm{PE}$ is not restricted to certain areas, but it is necessary in all areas where potentially societal effects may be expected. Nevertheless, pre-aligning all areas of R\&D with public benefit may be superfluous or even counterproductive. Innovation, for example, is frequently a by-product of basic research and thus there is a distinct need for basic research to remain independent and free as it is very often not possible to discern a public value ex-ante. Some scientific knowledge may also not seem relevant for societal problem solving at the time it is produced, but may become relevant later if circumstances change or it is interlinked with other findings. Such research would encounter difficulties to prove public value in early stages of research and would therefore hardly be funded under a strict PE regime. Additionally, there is the argument that the questions of how, who and when to engage is only a timely one, as when a new product is introduced, the market decides. Yet, adhering to needs based innovation may help to avoid stranded investments.

At least since the so called participatory turn in the 1990's, PE in STI issues became widely accepted [64], and several successful case-studies, theoretical arguments and practical guidelines are reported [e.g. 65-69]. At the same time, a discourse about the necessity of PE in decision making processes emerged on EU-level, cumulating in constitutional norm in the Lisbon treaty [59]. Yet, democratization in the EU is counteracted by a strong trend towards elitism [70]. Despite widespread PE enthusiasm, scholarly and political debate developed various critical and hypercritical arguments. The most commonly identified shortcomings include that PE fails to deliver the aimed for results, such as gains in rationality, stimulating debate or actual impact on strategy and policy-making [41, 54, 57, 59, 60, 71-80]. Here, discrepancies particularly emerge, when bridging the gap between theory and practice $[81,82]$. Part of the problem is that participatory practices are often constructed as political alternatives, as 'they normally are not part of the institutions of parliamentary politics' [83]. Yet, legally required PE, for instance applied as a communication or conflict management tools may not show the necessary flexibility with respect to the timing of engagement. For instance, if a technology is already consolidated, PE aimed at shaping and controlling it may often be too late. Thus, a 
prevailing scholarly demand for the early involvement of multiple actors including the public in the innovation process is currently expressed in concepts such as RRI or upstream engagement [2, 84-87]. Nevertheless, such early engagement faces the challenge that effects of a respective technology cannot be assessed reliably before implementation [88]. Here, transdisciplinary Foresight, as a setting for early upstream engagement in strategy and policy programme development, offers resolve.

\section{Strategy and policy programme development as early entry point for public needs and values}

A vast array of methods for engaging multiple actors in the development of STI programmes such as Horizon2020 is available [89]. Participatory FTA approaches have shown their ability to effectively support priority setting in international research programme cooperation [90, 91]. Here, transdisciplinary Foresight and Co-creation offer a unique approach to shaping STI agendas. Collective utopian thought enables laypeople to look for the blue - imagining alternative ways of e.g. organizing livelihoods, relationships or development [92]. Such visioning exercises support moving the discussions' focus from immediate concerns towards shared explorations of a more sustainable future [42]. Analysing such collective visions allows for collecting tacit knowledge as well as social needs and values without being restricted to a specific technology or current feasibility issues [43]. Then, integrating the elicited knowledge and needs with stakeholders' and experts' knowledge serves for co-creating socially robust knowledge for orienting policy and strategy programming to strengthen responsible innovation. Such an FTA approach necessarily implies knowledge management, as it engages multiple actors, sectors and interests in 'finding, deploying, using and fusing - and, yes, even creating - knowledge' [93]. Designing ways to manage the challenges of such participatory knowledge co-creation is especially important.

\section{A citizen and multi-actor approach for co-creating responsible research agendas}

The applied method is reflexive and multi-modular, combining several inter- and transdisciplinary workshops and knowledge management phases in a co-creative Foresight process. It is based upon the CIVISTI-method-Citizens visions on Science, Technology and Innovation, which was first developed and applied in an EU-research project as a demand side approach producing policy advice for prioritising research topics in Horizon2020 [43, 60, 94]. The key feature of the method is a recursive feedback cycle that starts with citizens producing visions of desirable futures, which are then analysed for underlying needs and overarching topics. On basis of visions and the respective analysis, stakeholders and experts are engaged to create recommendations for STI policy making, which are than fed back to the citizens for evaluation and prioritisation. Defined roles for all participating actor groups are essential within the method; here, the term citizen is used as synonym for layperson, whereas stakeholders, experts and policymakers are summarized as multi-actors. An expert may be understood as a scientific actor with distinct expertise in the respective field, whereas stakeholders are societal and economic actors with a specific stake in the field.

After its first application in a pilot study in eight EU countries, the method was then further developed and adapted to case specific properties in regional, national and transnational contexts [95-97]. For instance, one study on autonomous living for older adults in future cities was conducted at regional level for the City of Vienna and entailed process innovations such as an open online consultation at the end of the project in order to engage a wider public in the final prioritisation process. In a national study aimed at informing the long term research agenda of the Austrian Agency for Health and Food safety, the initial vision building workshop was scaled down from two days to one and additional methods to foster creativity of participants were introduced. Also a scenario building phase was added to augment the integration of citizens' visions and experts' recommendations. The CIVISTI-method was again modified, enriched and readapted to the European scope within CIMULACT. In short, the project aims at cocreating socially robust needs based futures for the European research agenda by engaging citizens and multi-actors and thereby contributing to RRI and democratic STI governance. Additionally, the project is a testbed for public participationdeveloping, testing, training and assessing methods for citizen and stakeholder engagement [23].

In a highly deliberative collective visioning process, more than 1,088 citizens in 30 European countries were engaged and developed 179 visions of desirable futures [98]. Here, the method is not aiming at inviting a statistically representative sample of participants, but building a sample of maximum heterogeneity to include a high number of different perspectives. Thus, each national consultation invited around 36 participants, ensuring a high diversity within the following criteria: age, gender, education occupation and place of living. For example, six age groups were defined, ranging from 16 to 60 and older; to then have one member of each age group in all smaller working groups (table level). Four educational levels - pre-primary to higher education - and several occupation groups were defined to distribute participants at table level aiming at a high heterogeneity of backgrounds. The criterion of place of living ensured engaging city as well as country dwellers.

The national vision building workshops followed a standardised process, starting with several activities to foster 
Table 1 Exemplary technologies mentioned in citizens' visions and interlinked services

\begin{tabular}{|c|c|}
\hline Specific technologies mentioned in visions & Service they fulfil \\
\hline $\begin{array}{l}\text { Nuclear fusion, roads equipped with energy captors, } \\
\text { superconductors, green battery }\end{array}$ & $\begin{array}{l}\text { Accessible, affordable, abundant and } \\
\text { green energy }\end{array}$ \\
\hline $\begin{array}{l}\text { Teleportation, hover platforms, magnetic levitation, } \\
\text { light rail capsule, air vehicle, eco-hovercrafts, drones, } \\
\text { a bridge connecting Cyprus and Crete }\end{array}$ & $\begin{array}{l}\text { Fast, flexible, affordable, smart, reliable } \\
\text { and clean transport }\end{array}$ \\
\hline $\begin{array}{l}\text { Nano-technology, hibernation, revolutionary drugs, } \\
\text { implanted chips, joint and bones regeneration, } \\
\text { artificial implants }\end{array}$ & $\begin{array}{l}\text { Healthier, prolonged, equal living supported } \\
\text { by technology }\end{array}$ \\
\hline Robots & Support working and living environments \\
\hline Memory recovery, e-learning & Lifelong learning, strength based education \\
\hline Holograms Telecommuting, knowledge sharing platforms, & Improving interpersonal relationships, equality \\
\hline Device for reading thoughts & Fair dispute resolution \\
\hline $3 \mathrm{~d}$ printers, a universal material & Production autonomy, less consumption \\
\hline Cyber polling, e-voting, electronic referendum & Building trust in democracy, active citizenship \\
\hline
\end{tabular}

creativity and collect as many ideas as possible, such as brainstorming, an inspirational picture set or a dream voyage. Then, individual work was used as a stepping stone for deliberations and combined group works with several feedback loops. Standardized templates supported the process. The final output were six visions per country.

As a next step, to elicit implicitly and explicitly mentioned social needs within the visions, a workshop with 30 interdisciplinary researchers from the CIMULACT consortium was held. They were supported by several challengers from various related fields of work, and jointly identified cross cutting and underlying themes, which were then shaped into 29 social needs with direct references to the citizens visions [99]. This was achieved in a bottom up analysis following several steps of assessing the original visions individually and later in smaller working groups, extracting explicit and implicit topics and clustering them, always making sure to reference the produced content to the respective visions.

Based on visions and elaborated social needs 12 clusters of needs were built to support a large-scale co-creation workshop in which more than 100 experts, stakeholders and citizens developed scenarios for the future EU research agenda. Within this workshop participants were split into small working groups with around eight participants, representing a variety of perspectives. Experts and stakeholders were assigned to topics, while citizens chose freely. The scenario building process followed several steps transferring needs and visions into scenarios for future research with subsections such as research direction, research questions, or state of art of current research on the topic. Overall 48 scenarios were produced. These research scenarios will be enriched, validated and prioritized in a second round of public face to face as well as online consultations, engaging again a large variety of actors. Throughout the process, additional consultations are conducted with policy makers and program managers at EU level to ensure the best possible connection of the results of actual research programs. A pan European conference taking place in Brussels engaging EU policy makers will shape the research scenarios into the final output, prioritised research topics in call format, integrating knowledge of lays, experts and stakeholders. CIMULACT is a European consultation which draws from national engagement activities in two consultation phases. These national activities were connected to the European level twice: within the co-creation workshop, which engaged representatives from all 30 countries and in the upcoming pan European conference.

Due to the ongoing process and its vast scope of results, we will focus on results available to date-citizens' visions and inherent social needs - and apply our analysis to the implications for human centred technologies.

\section{The role of technology within citizens' visions and corresponding social needs}

The pathways of technological transformations are, as discussed above, at the same heavily dependent on expectations actors have, as well as the respective innovation ecosystems' constraints. The digital transformation, for example, promises greater efficiency, quality improvement of products and services, an extension of the scope of action, and not least an increase in quality of life in most areas of daily life: work, production, mobility, communication, etc. Science, technology and innovation (STI) agendas, such as Horizon 2020, create the framework conditions that drive such transformations continuously: 'The ICT innovation strategy under Horizon 2020 focuses on ensuring that the rapid changes occurring in ICT technology develop into tangible benefits for European citizens' [100]. But what could such tangible benefits actually look like? What should innovation do for society? How does STI have to be shaped so that basic values and social needs of 
Table 2 Examples for technology as supporter of change
Technology as enabler

Vision

$100 \%$ security of personal data against abuse - it will be achieved by an advanced technology

The robots are not replacing the people, since they are only built to ease the work and not to take it over

The city is self-sufficient because of renewable energy and technology advances

CZE3

Technological progress has allowed renewable energies to respond to everyone's demand

Developments in technology and medical sciences have prolonged people's lives and improved their quality of life

More advanced technology which will facilitate communication and relationships between people.

Technological development has evolved and contributed to finding solutions for better resource management and natural disaster prevention.

Technology has allowed free time for focusing on personal and collective development

HRV2

[...]by 2050, the quality of life will have improved tremendously for senior citizens aided by technology

Technologies at the disposal of education, in order to enable a learning process which is continuous and not limited to school classes

An easier access to advanced technologies, with more intuitive and functional interfaces.

A technology that fosters face-to-face relationships instead of virtual ones, em-powering actual sociality

Profits from patents are used to disseminate education and popularization of science and technology

Digital innovations are used to support learning processes

ESP6

FR2

FIN2

BGR3

POR1

POR4

ROU4

ITA6

ITA6

[...] technological development has contributed to a significant increase of self-treatment/ autonomy, and with this also social equality

Technology will develop in harmony with the environment and individuals' needs

Technology does not alienate people and does not endanger their health

[..] regulate the role of new technologies in order to avoid damaging the quality of human relationships

Technological developments are making working process easier, but not taking away jobs from the humans

The development of new technologies, in accordance with the laws of nature, will lead to the improved quality of life

The high-tech knowledge we have acquired, is being channelled into new solutions. By using all resources (people, technology, money), continued welfare and sustainable growth is created

Our level of industrial and technological development allows us to better combine a shorter working day, time dedicated to child education and a freely chosen contribution to our community

Universal material and technologies allow us to remake old things and turn them into new ones.[...] This invention frees society from the use of the surplus and creates conditions for harmonious personalities

Living in a society in which technology helps people throughout all aspects of life (food, health, environment, economic activity) in order to afford the "luxury" of investing in personal development

In 2050, the technological and scientific breakthroughs have led to: minimised pollutionair pollution, water pollution, domestic waste; the use of clean energy sources - growth of the share of renewable and sustainable energy; clean food and water-self-evident and available for everybody; environmentally friendly means of transport- public transport solutions, fuel; a change in the nature of work - a shorter workday, contribution to socie-ty/social dimension citizens are taken into account? How can research agendas be designed in a more democratic way? These are some of the questions CIMULACT aims at answering.

Here, it is important to clarify the tasks a collective transdisciplinary visioning process can fulfil and which it may not. The citizens' duty is focussed upon imagining a desirable future and thereby expressing needs and demands towards current as well as future developments. If a specific technology is mentioned by citizens while visioning, it is not necessarily this technology that plays the visionary part in the desirable imaginary, but often rather the service it offers and therefore which need it fulfils. For instance, there is nuclear fusion 
mentioned (Austria vision 1), but the context it appears in as well as connecting it to other visions implies an underlying need for: 'accessible, affordable, abundant and green energy' [101]. Here is an example that shows the focus on a service, not a technology: 'Grandpa Paul was saved from a disease that was incurable 35 years ago, by using nanotechnology. Cancer is now a common cold' [Romania vision 6].

Here, it is not the citizens' duty to identify certain technologies that can satisfy this need, but expressing the need in the first place. Another example the same reasoning applies for, is the demand for 'fast, flexible, affordable, smart, reliable and clean transport' systems (social need 14). At first sight this may sound like an oxymoron, but again it is citizens setting a landmark by describing a desirable long term future. By orienting STI towards this landmark may help fulfilling social needs, guiding the innovation system in a socially responsible way, even if the actual technology mentioned in the citizens' visions - teleportation, hover boards or a bridge connecting Cyprus and Crete - is never implemented. Another example is the mentioned hibernation or implanted chips. Here, when overseeing all visions the cross cutting theme of healthier, prolonged, equal living which is supported by technology emerges. Table 1 shows mentioned technologies as well as the services they are aimed at fulfilling. ${ }^{1}$

\section{Technology as enabler and supporter not as main focus of change}

Even if we focussed on the role of technology within the visions and corresponding social needs as a tacit example, it should be recognized that particular technologies are not the citizens' main focus when imagining desirable futures. Mostly, when science and technology are mentioned - if they are mentioned at all - they are seen as an entity that in the best case can facilitate progress and support a better living. The following Table 2 shows selected excerpts from visions to provide some examples. Within these examples several additional demands and expectations towards technology development may be found, yet some statements also shed light on current shortcomings and fears towards technology.

Being forced to develop desirable futures, citizens frame such fears or shortcomings of current developments positively, but they are still perceivable as such: 'Robots are not replacing people, since they are only built to ease the work and not to take it over.' Or 'Technology does not alienate people and does not endanger their health.'

Other examples show a different angle, the mentioned security against personal data abuse, for instance. Within the vision an advanced technology is imagined to provide

\footnotetext{
${ }^{1}$ For the full text of all visions in English consult Deliverable 1.3 - Vision Catalogue [98], for national languages consult the national reports on citizens' vision workshops [101].
}

$100 \%$ security. Following current experts' discourse on the matter reveals that often user behaviour is seen as one of the main challenges for providing security. Yet again if laypeople state 'science and/or technology should solve the problem' when depicting desirable futures, this should not necessarily be narrowed down to actual technologies, but may be seen in the larger context of innovation. Here, social, technical as well as organisational innovations may take the role of enabling solutions for the expressed demands and fears.

\section{Conclusions}

Overall, technologies addressed by citizens may sometimes seem far out and borrowed from sci-fi literature or movies, as teleportation. Here, such specific technologies should therefore in many cases be seen as placeholders for viable solutions that address fulfilling the indicated needs. Here, social, technical as well as organisational innovations may take the role of enabling solutions for the expressed demands and fears. On the other hand, some technologies mentioned are already available or very common in experts' debate, for instance elearning. Here, citizens mostly see their potential and wish for a wide distribution and common equal availability, or simply adjustments to the current state, such as avoiding personal data misuse.

We described the merits of including public engagement into Futures Studies, especially when stakes are high and vast societal implications can be expected. Dealing with the Grand Challenges requires socially robust knowledge, therefore including a broad basis of actors is advisable, not neglecting laypeople's knowledge, experience and opinion. In addition to stakeholders' and experts knowledge, socially robust knowledge can thus be co-created, from which tangible policy advice for science, technology and innovation governance derives. Here, clear limits of public engagement become obvious. PE in Futures Studies - transdisciplinary Foresightserves well as a starting point to elicit public values and social needs, but further integration with the established forms of scientific knowledge as well as stakeholder engagement is absolutely necessary. Yet, this implies a complex knowledge management regime, where roles of actors are clearly delimitated and rules of discussion and knowledge integration need to be transparent and fair. In this respect, CIMULACT provides an interesting mix of actors, but here, further research is needed to i.e. evaluate power balance between groups.

Overall, processes such as CIMULACT may mitigate the much stressed shortcoming of public engagement to not provide real impacts on policy making. A large actor basis, as built in CIMULACT, supports creating ownership of results among the actors themselves and building trust in them outside of the immediate participants. Yet, it is established that impacts of policy advice in general, and the ones produced by 
public engagement activities in particular, are hard to measure [102], especially when considering a forward looking long term perspective and an emphasis on system level [14]. Nevertheless that does not mean that impacts do not exist. An evaluation of the projects' methodology as well as an impact assessment will be available by mid-2017. With regard to CIMULACT, real interest by the European Commission can be observed, proofed by first soliciting such a project and secondly by actively being interested the projects' progress and intermediate results. Yet, gate keepers power over the flow of knowledge become once again obvious, as it needs single interested and dedicated persons in the right positions who actively seek integration of such socially robust cocreated knowledge to further sustainable and responsible innovation agendas.

Via this pathway, impact among economic actors may be generated, although impacts may not have the aimed for high degree of dispersion in the current still small scale experimental phase. Compared to the many public private partnerships that have great lobbying power within the EU-research funding scheme, research and policy advice such as conducted under CIMULACT may become negligible. Yet, it shows, how the political concept of RRI can be filled with meaning, accountability and life, thereby serving as a landmark itself, providing guidance for sustainable long term futures.

Open Access This article is distributed under the terms of the Creative Commons Attribution 4.0 International License (http:// creativecommons.org/licenses/by/4.0/), which permits unrestricted use, distribution, and reproduction in any medium, provided you give appropriate credit to the original author(s) and the source, provide a link to the Creative Commons license, and indicate if changes were made.

\section{References}

1. Boden M, Johnston R, Scapolo F (2012) The role of FTA in responding to grand challenges: a new approach for STI policy? Sci Public Policy 39:135-139. doi:10.1093/scipol/scs026

2. Owen R, Macnaghten P, Stilgoe J (2012) Responsible research and innovation: from science in society to science for society, with society. Sci Public Policy 39:751-760. doi:10.1093/scipol/scs093

3. von Schomberg R (ed) (2011) Towards responsible research and innovation in the information and communication technologies and security technologies fields. Publications Office of the European Union, Luxembourg. http://ec.europa.eu/research/sciencesociety/document_library/pdf_06/mep-rapport-2011_en.pdf. Accessed 23 Nov 2011

4. von Schomberg R (2013) A vision of responsible research and innovation. In: Owen R, Bessant J, Heintz M (eds) Responsible innovation: managing the responsible emergence of science and innovation in society. John Wiley \& Sons Ltd, Chichester, pp 5173. doi: $10.1002 / 9781118551424 . c h 3$

5. Stahl BC (2014) Responsible research and innovation: the role of privacy in an emerging framework. Sci Public Policy 40:708-716. doi:10.1093/scipol/sct067
6. RRI-Tools (2016) RRI Toolkit - Built with and for the Community of Practice http://www.rri-tools.eu/search-engine\#keywords= foresight@filterOption=@order=@page=. Accessed 29 June 2016

7. Lindner R, Kuhlmann S, Randles S, Bedsted B, Gorgoni G, Griessler E, Loconto A, Mejlgaard N (2016) Navigating towards shared responsibility in research and innovation- approach, process and results of the RES-AGorA project. Fraunhofer ISI, Karlsruhe, http://publica. fraunhofer.de/dokumente/N-382937.html

8. Weber KM, Harper JC, Könnöla T, Barcelo V (2012) Coping with a fast-changing world: towards new systems of future-oriented technology analysis. Sci Public Policy 39:153-165. doi:10.1093 /scipol/scs012

9. Haegeman K, Weber M, Könnölä T (2012) Preparing for grand challenges: the role of future-oriented technology analysis in anticipating and shaping structural and systemic changes. Tech Anal Strat Manag 24:729-734. doi:10.1080/09537325.2012.715475

10. Cagnin C, Amanatidou E, Keenan M (2012) Orienting European innovation systems towards grand challenges and the roles that FTA can play. Sci Public Policy 39:140-152

11. Georghiou L, Harper JC (2011) From priority-setting to articulation of demand: foresight for research and innovation policy and strategy. Futures 43:243-251

12. Cagnin C, Johnston R, Giesecke S (2015) Foresight contribution to grand challenges and participative governance in different cultural settings. Technol Forecast Soc Chang 101:182-184

13. Grunwald A (2011) Responsible innovation: bringing together technology assessment, applied ethics, and STS research. Enterprise and Work Innovation Studies 7: 9-31

14. Könnölä T, Scapolo F, Desruelle P, Mu R (2011) Foresight tackling societal challenges: impacts and implications on policy-making. Futures 43:252-264

15. Alkemade F, Suurs RAA (2012) Patterns of expectations for emerging sustainable technologies. Technol Forecast Soc Chang 79:448-456. doi:10.1016/j.techfore.2011.08.014

16. Geels FW, Kern F, Fuchs G, Hinderer N, Kungl G, Mylan J, Neukirch M, Wassermann S (2016) The enactment of sociotechnical transition pathways: a reformulated typology and a comparative multi-level analysis of the German and UK low-carbon electricity transitions (1990-2014). Res Policy 45:896-913. doi:10.1016/j.respol.2016.01.015

17. Borup M, Brown N, Konrad K, Van Lente H (2006) The sociology of expectations in science and technology. Tech Anal Strat Manag 18: 285-298

18. Verbong G, Geels F, Raven R (2008) Multi-niche analysis of dynamics and policies in Dutch renewable energy innovation journeys (1970-2006). Tech Anal Strat Manag 20:555-573

19. van Lente H, Spitters C, Peine A (2013) Comparing technological hype cycles: towards a theory. Technol Forecast Soc Chang 80: 1615-1628. doi:10.1016/j.techfore.2012.12.004

20. Könnöla T, Salo A, Cagnin C, Carabias V, Vilkkumaa E (2012) Facing the future: scanning, synthesizing and sense-making in horizon scanning. Sci Public Policy 39:222-231. doi:10.1093 /scipol/scs021

21. Boden M, Cagnin C, Carabias V, Haegeman K, Könnöla T (2010) 'Facing the future: time for the EU to meet global challenges', 24364 EN, 6/2010. Luxembourg: Office for Official Publications of the European Commission

22. Jasanoff S, Kim S (2009) Containing the atom: sociotechnical imaginaries and nuclear power in the United States and South Korea. Minerva 47:119-146

23. CIMULACT (2016) Citizen and Multi-Actor Consultation on Horizon 2020. http://www.cimulact.eu/. Accessed 30 June 2016

24. Nowotny H (2003) Dilemma of expertise. Democratising expertise and socially robust knowledge. Sci Public Policy 30:151-156 
25. Scapolo F, Miles I (2006) Eliciting experts' knowledge: a comparison of two methods. Technol Forecast Soc Chang 73:679-704. doi:10.1016/j.techfore.2006.03.001

26. Nennen HU, Garbe D (1996) Das Expertendilemma: Zur Rolle wissenschaftlicher Gutachter in der öffentlichen Meinungsbildung. Springer, Berlin

27. Grunwald A (2003) 'Experts' dilemma'. Technology assessment at the German Bundestag: 'expertising' democracy for 'democratising' expertise. Sci Public Policy 30:193-198

28. Grunwald A (2014) Modes of orientation provided by futures studies: making sense of diversity and divergence. Eur J Futures Res 15:30. doi:10.1007/s40309-013-0030-5

29. Fye SR, Charbonneau M, Hay J, Mullins C (2013) An examination of factors affecting accuracy in technology forecasts. Technol Forecast Soc Chang 80:1222-1231

30. Goldstein D, Gigerenzer G (2009) Fast and frugal forecasting. Int J Forecast 25:760-772

31. Makridakis S, Taleb N (2009) Decision making and planning under low levels of predictability. Int J Forecast 25:716-733

32. Tuominen A, Wessberg N, Leinonen A (2015) Participatory and prospective value network analysis: supporting transition towards biofuels in Finnish road transport. Eur J Futures Res 3:6. doi:10.1007/s40309-015-0064-y

33. Nordmann A (2014) Responsible innovation, the art and craft of anticipation. J Responsible Innov 1:87-98. doi:10.1080 /23299460.2014.882064

34. Nowotny H, Scott P, Gibbons M (2001) ReThinking science. Knowledge and the public in an age of uncertainty. Polity Press, Cambridge

35. Taebi B, Correljé A, Cuppen E, Dignuma M, Pesch U (2014) Responsible innovation as an endorsement of public values: the need for interdisciplinary research. J Responsible Innov 1:118 124. doi: $10.1080 / 23299460.2014 .882072$

36. Dignum M, Correljé A, Cuppen E, Pesch U, Taebi B (2015) Contested technologies and design for values: the case of shale gas. Sci Eng Ethics 1-21. doi:10.1007/s11948-015-9685-6

37. Polk M (2015) Transdisciplinary co-production: designing and testing a transdisciplinary research framework for societal problem solving. Futures 65:110-122

38. Nikolova B (2014) The rise and promise of participatory foresight. Eur J Futures Res 15:33. doi:10.1007/s40309-013-0033-2

39. Popp R (2013) Participatory futures research. Research or practice consulting? Eur J Futures Res 1:16. DOI 10.1007/s40309-0130016-3

40. List D (2006) Action research cycles for multiple futures perspectives. Futures 38:673-684

41. Irwin A (2001) Constructing the scientific citizen: science and democracy in the biosciences. Public Underst Sci 10:1-18

42. Eames M, Egmose J (2011) Community foresight for urban sustainability: insights from the citizens science for sustainability (SuScit) project. Technol Forecast Soc Chang 78:769-784

43. Gudowsky N, Peissl W, Sotoudeh M, Bechtold U (2012) Forwardlooking activities: incorporating citizens' visions. Poiesis Prax 9: 101-123. doi:10.1007/s10202-012-0121-6

44. Guillo M (2013) Futures, communication and social innovation: using participatory foresight and social media platforms as tools for evaluating images of the future among young people. Eur $\mathrm{J}$ Futures Res 1:17

45. Cabrera Trujillo YL (2014) Visioneering and the role of active engagement and assessment. NanoEthics 8(2):201-206. doi:10.1007/s11569-014-0199-5

46. Heidingsfelder M, Kimpel K, Best K, Schraudner M (2015) Shaping future - adapting design know-how to reorient innovation towards public preferences. Technol Forecast Soc Chang 101: 291-298. doi:10.1016/j.techfore.2015.03.009
47. Levitas R (2013) Utopia as method: the imaginary reconstitution of society. Palgrave Macmillan, Basingstoke

48. Nicolescu B (2014) Methodology of transdisciplinarity. World Futures 70:186-199. doi:10.1080/02604027.2014.934631

49. Funtowicz SO, Ravetz JR (1993) Science for the post-normal age. Futures 25:739-755

50. Gibbons M, Limoges C, Nowotny H, Schwartzman S, Scott P, Trow M (1994) The new production of knowledge: the dynamics of science and research in contemporary societies. Sage, London

51. McGregor SLT, Donnelly G (2014) Transleadership for transdisciplinary initiatives. World Futures 70:164-185. doi:10.1080 /02604027.2014.934625

52. Fiorino DJ (1990) Citizen participation and environmental risk: a survey of institutional mechanisms. Sci Technol Hum Values 15: 226-243

53. Rowe G, Frewer LJ (2005) A typology of public engagement mechanisms. Sci Technol Hum Values 30:251-290

54. Abels G (2007) Citizen involvement in public policy-making: does it improve democratic legitimacy and accountability? The case of PTA. Interdiscip Inf Sci 13:103-116

55. Bobbio L (2010) Types of deliberation. J Public Deliberation 6:1, http://services.bepress.com/cgi/viewcontent.cgi?article=1117 \&context=jpd

56. Monaghan E (2012) Assessing participation and democracy in the EU: the case of the European citizens' initiative. Perspect Eur Politics Soc 13:285-298

57. Boussaguet L (2016) Participatory mechanisms as symbolic policy instruments? Comp Eur Polit 1:107-124

58. Wiek A, Iwaniec D (2013) Quality criteria for visions and visioning in sustainability science. Sustain Sci 9:497-512

59. Saurugger S (2010) The social construction of the participatory turn: the emergence of a norm in the European Union. Eur J Polit Res 49:471-495

60. Rask M (2013) The tragedy of citizen deliberation - two cases of participatory technology assessment. Tech Anal Strat Manag 25: 39-55. doi:10.1080/09537325.2012.751012

61. Lawrence RJ (2015) Advances in transdisciplinarity: epistemologies, methodologies and processes. Futures 65:1-9

62. Lang DJ, Wiek A, Bergmann M, Stauffacher M, Martens P, Moll P, Swilling M, Thomas CJ (2012) Transdisciplinary research in sustainability science: practice, principles, and challenges. Sustain Sci 7(Supplement 1):25-43. doi:10.1007/s11625-011-0149-x

63. Brandt P, Ernst A, Gralla F, Luederitz C, Lang DJ, Newig DJ, Reinert F, Abson DJ, von Wehrden H (2013) A review of transdisciplinary research in sustainability science. Ecol Econ 92:1-15. doi:10.1016/j.ecolecon.2013.04.008

64. Jasanoff S (2003) Technologies of humility: citizens participation in governing science. Minerva 41:223-244

65. Hennen L (2002) Impacts of participatory technology assessment on its social environment. In: Joss S, Bellucci S (eds) Participatory technology assessment-European perspectives. University of Westminster Press, London, pp 257-275

66. Decker M, Ladikas M (2004) Bridges between science, society and policy. Technology assessment - methods and impacts. Springer, Berlin

67. Goodin R (2008) Innovating democracy. Democratic theory and practice after the deliberative turn. Oxford University Press, New York

68. Stilgoe LSJ, Wilsdon J (2014) Why should we promote public engagement with science? Public Underst Sci 23:4-15

69. Burgess MM (2014) From 'trust us' to participatory governance: deliberative publics and science policy. Public Underst Sci 23:48-52

70. Pausch M (2014) Democratization and elitism in the EU: two opposing trends (Guest-Editor's introduction to the topical collection on "The Future of Europe"). Eur J Futures Res 2:56. doi:10.1007/s40309-014-0056-3 
71. Grunwald A (2004) Participation as a means of enhancing the legitimacy of decisions on technology? A sceptical analysis. Poiesis Prax 3:106-122

72. Wynne B (2007) Public participation in science and technology: performing and obscuring a political-conceptual category mistake. East Asian Sci Technol Soc 1:99-110

73. Irwin A, Jensen TE, Jones KE (2013) The good, the bad and the perfect: criticizing engagement practice. Soc Stud Sci 43:118-135

74. Bora A, Hausendorf H (2006) Participatory science governance revisited: normative expectations versus empirical evidence. Sci Public Policy 33:478-488. doi:10.3152/147154306781778740

75. Goodin RE, Dryzek JS (2006) Deliberative impacts: the macropolitical uptake of mini-publics. Pol Soc 34:219-244. doi:10.1177 /0032329206288152

76. Lengwiler M (2008) Participatory approaches in science and technology: historical origins and current practices in critical perspective. Sci Technol Hum Values 33:186-200. doi:10.1177 /0162243907311262

77. Bogner A (2012) The paradox of participation experiments. Sci Technol Hum Values 37:506-527

78. Bagg S (2015) Can deliberation neutralise power? Eur J Polit Theor 1-23. doi:10.1177/1474885115610542

79. Krabbenborg L, Mulder HAJ (2015) Upstream public engagement in nanotechnology: constraints and opportunities. Sci Commun 37:452-484. doi:10.1177/1075547015588601

80. Wang X (2016) Revisiting upstream public engagement from a habermasian perspective. NanoEthics 10:63-74. doi:10.1007 /s11569-015-0239-9

81. Chilvers J (2008) Deliberating competence-theoretical and practitioner perspectives on effective participatory appraisal practice. Sci Technol Hum Values 33:155-185. doi:10.1177/0162243907307594

82. Delgado A, Lein Kjølberg K, Wickson F (2010) Public engagement coming of age: from theory to practice in STS encounters with nanotechnology. Public Underst Sci 20:826-845

83. Bora A, Hausendorf H (2010) Democratic Transgressions of Law: Governing Technology Through Public Participation. Leiden \& Boston: Brill 2010, ISBN 978-9004180437.

84. Hagendijk R, Irwin A (2006) Public deliberation and governance: engaging with science and technology in contemporary Europe. Minerva 44:167-184. doi:10.1007/s11024-006-0012-x

85. Wilsdon J, Willis R (2004) See-through science: why public engagement needs to move upstream. Demos, London

86. Pidgeon N, Rogers-Hayden T (2007) Opening up nanotechnology dialogue with the publics: risk communication or "upstream engagement"? Health Risk Soc 9:191-210

87. Escobar O (2014) Upstream public engagement, downstream policy-making? The Brain Imaging Dialogue as a community of inquiry. Sci Public Policy 41:480-492

88. Collingridge D (1980) The social control of technology. London

89. Engage 2020 Consortium (2015) Engage2020 - tools and instruments for a better societal engagement in "Horizon 2020", Engaging Society in Horizon 2020. D3.2 Public Engagement Methods and Tools. http://engage2020.eu/media/D3-2-PublicEngagement-Methods-and-Tools-3.pdf. Accessed 10 Sept 2016
90. Könnöllä T, Haegeman K (2012) Embedding foresight in transnational research programming. Sci Public Policy 39:191-207. doi:10.1093/scipol/scs020

91. Haegeman K, Spiesberger M, Veselitskaya N, Sokolov A, Weiss G (2015) FTA supporting effective priority setting in multi-lateral research programme cooperation: The case of EU-Russia S\&T cooperation. Technol Forecast Soc Chang 101:200-215

92. Levitas R (2007) Looking for the blue: the necessity of utopia. J Political Ideologies 12:289-306. doi:10.1080/13569310701622184

93. Eerola A, Miles I (2011) Methods and tools contributing to FTA: a knowledge-based perspective. Futures 43:265-278

94. CIVISTI (2008) Project website. www.civisti.org. Accessed 9 June 2016

95. Gudowsky N, Bechtold U, Capari L, Sotoudeh M (2015b) Participatory foresight. Experiences with a qualitative demand-side approach. In: Scherz C, Michalek T, Hennen L, Hebáková L, Hahn J (eds) The next horizon of technology assessment. Proceedings from the PACITA 2015 Conference in Berlin. Technology Centre ASCR, Prague, pp 139-143, p. 426 (Ref.)

96. Gudowsky N, Sotoudeh M (2015) Citizens' Visions on Active Assisted Living. In: Hayn D, Schreier G, Ammenwerth E, Hörbst A (eds) eHealth2015 - Health Informatics Meets eHealth. Studies in Health Technology and Informatics 212, Amsterdam: IOS, pp 43 - 49. doi 10.3233/978-1-61499-524-143Gudowsky N, Sotoudeh M (2016) Transdisciplinary Foresight - Co-Creating Research Agendas Using Multi-Actor Engagement. European Foresight Platform (ed) EFP Brief No. 262. http://www.foresight-platform.eu/brief/efp-brief-no-262transdisciplinary-foresight-co-creating-research-agendas-usingmulti-actor-engagement/

97. CASI (2016) CASI - Public Participation in Developing a Common Framework for Assessment and Management of Sustainable Innovation. www.casi2020.eu. Accessed 30 June 2016

98. Jørgensen ML, Schøning S (2016) CIMULACT Deliverable 1.3 - Vision Catalogue- Encompassing the visions from all 30 countries. http://www.cimulact.eu/wp-content/uploads/2016/06/D1.3 final.pdf. Accessed 18 Oct 2016

99. CIMULACT (2016b) Poster of the 29 extracted European citizens' needs. http://www.cimulact.eu/wp-content/uploads/2016 /04/Cimulact_ALL_POSTER_SOCIAL_NEEDS_reduced.pdf. Accessed 30 June 2016

100. European Commission (2016) ICT innovation in horizon 2020 https://ec.europa.eu/digital-single-market/ict-innovation-horizon2020

101. CIMULACT (2016c) National reports on citizens vision workshops. http://www.cimulact.eu/national-reports-on-the-citizenvision-workshops/. Accessed 30 June 2016

102. Emery SB, Mulder HAJ, Frewer LJ (2015) Maximizing the policy impacts of public engagement: a European study. Sci Technol Hum Values 40:421-444. doi:10.1177/0162243914550319 